\title{
UM OLHAR SINTETIZADO SOBRE A MODALIDADE DE ENSINO EAD E O PAPEL DE SEUS AGENTES - PROFESSOR E ALUNO
}

\author{
Tania Pleszko Janusis ${ }^{1}$
}

\section{RESUMO}

Neste escrito, será apresentado um breve relato sobre a modalidade de Educação a Distância EAD e seus benefícios para a formação e capacitação do homem, além de apontar algumas diferenças entre esta modalidade de ensino e a presencial, enfatizando, especialmente, a questão da democratização do ensino para todos, o perfil esperado do aluno e o papel do professor desta modalidade. Assim, espera-se que a percepção dos agentes inseridos nessa modalidade possa ser efetivada de modo mais sensível e que considere ambos, o professor e o aluno, como elementos essenciais para o ensino.

Palavras-chave: Educação a Distância; Modalidades de Ensino; Perfil do Aluno; Papel do Professor.

\section{ABSTRACT}

In this writing, a brief report will be presented on the modality of Distance Education -Distance Education -EAD and its benefits for the training and training of men, besides pointing out some differences between this modality and the face-to-face, emphasizing, especially, the issue of the democratization of teaching for all, the expected profile of the student and the role of the teacher of this modality. Thus, it is expected that the perception of the agents inserted in this modality can be effected in a more sensitive way and that considers both the teacher and the student as essential elements for teaching.

Keywords: Distance Education; Teaching modalities; Student Profile; Role of the Professor.

\section{RESUMEN}

En este escrito, se presentará un breve informe sobre la modalidad de Educación a Distancia Educación a Distancia -EAD y sus beneficios para la formación y formación de hombres, además de señalar algunas diferencias entre esta modalidad y la presencial, destacando, especialmente, el tema de la democratización de la enseñanza para todos, el perfil esperado del alumno y el papel del docente de esta modalidad. Así, se espera que la percepción de los agentes insertados en esta modalidad pueda realizarse de una manera más sensible y que considere tanto al profesor como al alumno como elementos esenciales para la enseñanza.

Palabras clave: Educación a Distancia; Modalidades de enseñanza; Perfil del estudiante; Papel del Profesor.

\footnotetext{
${ }_{1}$ Pedagoga e especialista em Neuropsicopedagogia, Professora da rede pública de São Paulo. E-mail: tania.13pj@gmail.com
} 


\section{INTRODUÇÃO}

Como é de conhecimentos de todos nós, a evolução da tecnologia transformou a vida do homem nos mais diversos aspectos. Entre eles, destacam-se sua relação familiar, profissional, cultural e acadêmica, impactando em tópicos importantes como tempo, custos e facilidade de acesso.

Enfatizando a questão da formação e capacitação do homem, por meio dos recursos tecnológicos, pode-se afirmar que estes fatos já se faziam presentes há muito tempo em nosso meio, desde as aulas desenhadas e projetadas pelos telecursos, nos quais os materiais das aulas eram enviados para os alunos pelo correio, para que pudessem estudar em seus lares, recorrendo às aulas gravadas em fitas cassetes, CDs ou pela leitura dos materiais impressos como livros e apostilas.

Foi a partir dos anos 80 , a tecnologia educacional passou a ser assimilada como uma opção de se fazer educação (grifo nosso), visando o desenvolvimento integral do homem e sua inserção crítica no mundo em que vive (MORAIS, 2018).

Com o avanço da tecnologia, em especial impulsionado pela internet, os cursos e as aulas passaram a ser ainda mais dinâmicos e de fácil acesso, permitindo que um número maior de pessoas pudesse se capacitar ou concluir uma formação técnica e superior.

Sobre isso, segundo Moraes (2018):

No início do século XIX o Brasil utilizava o correio como forma de educação a distância, algumas pesquisas mostram que existiam anúncios em jornais do Rio de Janeiro que ofertavam cursos profissionalizantes por meio de correspondências, eram cursos de datilografia ministrados por professores particulares, sem fazer uso de um estabelecimento de ensino. Com o passar do tempo e a evolução das tecnologias disponíveis, foram utilizados: o rádio, TV, rede local, mídias de armazenamento (VHS, disquete, CD-ROM), somente ao final do século a Internet. A educação a distância tornou-se mais atrativa com o surgimento da Internet, as perspectivas de ampliação e crescimento aumentaram significativamente, junto com as facilidades proporcionadas por esta tecnologia. A incorporação de novas tecnologias computacionais de comunicação possibilitou o desenvolvimento dos ambientes virtuais de aprendizagem (AVA) como novos meios de apoio ao aprendizado à distância (MORAES, 2018). 
Diante destes acontecimentos, a modalidade de ensino EAD (Educação a Distância) garantiu um lugar de destaque no seio educacional/formal. Por isso, aproveitaremos este espaço para discorrer sobre essa modalidade e seus benefícios, além de apontar algumas diferenças entre a modalidade presencial, enfatizando a questão da democratização do ensino e o papel dos seus envolvidos.

Conforme Moraes (2002), o uso do AVA oferece as vantagens:
A interação entre o computador e o aluno;
A possibilidade de se dar atenção individual ao aluno;
A possibilidade de o aluno controlar seu próprio ritmo de aprendi- zagem, assim como a sequência e o tempo;
A apresentação dos materiais de estudo de modo criativo, atrativo e integrado, estimulando e motivando a aprendizagem;
A possibilidade de ser usada para avaliar o aluno (MORAES, 2002).

Em sua essência, o ensino a distância se estrutura em bases como: economia, flexibilidade de tempo e espaço, inovação comodidade. Essa modalidade de ensino é flexível por permitir que o aluno tenha liberdade para assistir e rever às aulas no momento e local que melhor se ajustar a sua rotina, através de sua plataforma de ensino.

Assim, ampliando essa visão de vantagens desta modalidade de ensino, recorremos a Kenski (2003) que diz:

O homem transita culturalmente mediado pelas tecnologias que lhe são contemporâneas. Elas transformam suas maneiras de pensar, sentir, agir. Mudam também suas formas de se comunicar e de adquirir conhecimentos (KENSKI, 2003, p. 21).

Essa realidade é distinta da sala de aula tradicional, onde as aulas são ministradas em um horário e local pré-fixado e específico, implicando gastos com locomoção, desgastes no trajeto e tempo.

\section{PERFIL QUE DEVE TER O ALUNO E O PROFESSOR PARA TER SU- CESSO NA EAD}

O papel de todos os agentes neste processo exige responsabilidades, organização do tempo e disposição para ampliar seus horizontes, apropriando-se dos recursos que as plataformas de ensino podem propor a eles. 


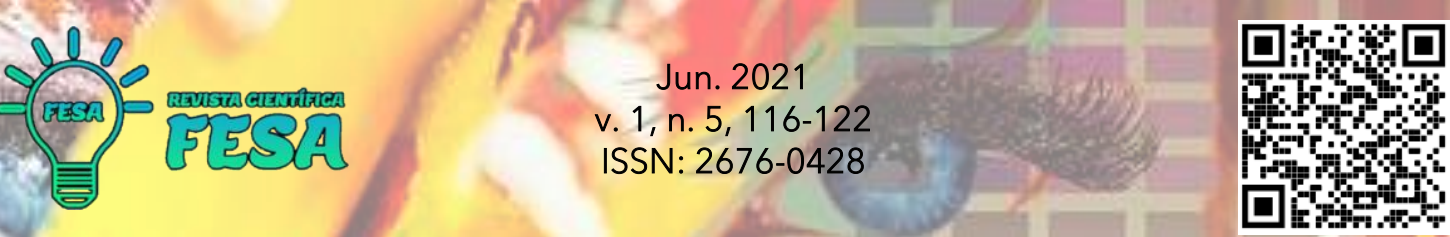

Aos alunos, recai a tarefa de organizar seu tempo para estudar os conteúdos propostos, participar de fóruns, chats, fazer leitura dos materiais das aulas e assistir aos vídeos dispostos em seu ambiente virtual de estudo. Assim, ele será o principal ator de sua formação, tendo a tarefa de ser ativo em todas as etapas e momentos deste trajeto.

Já ao professor, fica o dever de se atualizar quanto ao uso das ferramentas pedagógico-digitais (mídias), preparar os conteúdos das aulas, estar disponível para dar suporte as dúvidas dos alunos, incentivá-los a se apropriarem dos recursos e materiais dispostos em seu ambiente de estudo, além de sondar como o processo é o desenvolvimento do aluno está ocorrendo.

Em se tratando da flexibilidade que o ensino a distância pode propiciar, especialmente para as pessoas que não dispõem de um tempo fixo todos os dias para se deslocar a um centro de ensino, cabe destacar que nesta modalidade de ensino recai sobre o discente a responsabilidade de lidar com a autonomia neste processo por serem os maiores responsáveis pelo aproveitamento do seu estudo.

Dessa maneira, ele terá que ser mais ativo em todos os momentos do curso, planejando seus horários de estudos, usando o tempo e a liberdade de maneira responsável e produtiva.

Essa postura ativa exigida do aluno também reflete no papel do professor que, passa a servir de ponte entre o aluno e os conhecimentos, saindo de cena como o ator principal do processo de ensino e aprendizagem, permitindo que o aluno seja o destaque de sua formação, o agente do seu saber.

Azevedo (2000) aponta dois modelos pedagógicos: presencial x EAD, aclarando que o primeiro se fundamenta na transmissão de informação e é a base da educação. O segundo é o modelo em que o aluno aprende aquilo que lhe é transferido a partir de um objetivo de transmissão, recorrendo ao docente como fonte de saber para sanar suas eventuais dúvidas.

Já o meio de ensino colaborativo trilha os percursos da interação e da parceria entre docentes e discentes. Dessa forma, o aprendizado se dá por meio da construção coletiva a partir de discussões críticas, problematizações, questionamentos, apresentação de dúvidas e troca de informações coesas e coerentes. 
Diante dessa realidade, acredita-se que a diferença primordial entre os alunos dos cursos nas modalidades EAD e presenciais está na forma como esses agentes lidam com o aprendizado através dos recursos e meios dispostos a sua formação, pois pelo próprio modelo do ensino a distância, o estudante é estimulado a ter uma postura mais ativa diante do conhecimento. Sem horário fixo de aula e sem a figura do professor presente o tempo todo, ele tem que "correr atrás" do conteúdo e assumir uma atitude mais participativa. Já no presencial, o ritmo é outro. Com horários estabelecidos e professores em sala, há um modelo diferente de interação e de troca de conhecimento.

Nem todos os alunos interagem em sala. O conteúdo transmitido ali não fica completamente registrado e, exceto pelos cadernos e livros, o estudante não tem como acessá-lo mais tarde, caso precise.

Por fim, para ter sucesso na modalidade de ensino EAD, o aluno precisa deixar de ser passivo, para ser o construtor de seu conhecimento. Portanto, a ênfase da educação deixa de ser a memorização da informação transmitida pelo professor e passa a ser a construção do conhecimento realizada pelo aluno de maneira significativa, sendo o professor o facilitador desse processo de construção.

\section{ATITUDES QUE DEVEM SER ABANDONADAS PARA SER UM BOM ALUNO NO CONTEXTO DIGITAL}

Acredita-se que para ter êxito nessa modalidade de ensino o discente precisa deixar de lado: a dependência do professor e seu norte; a dependência da estrutura curricular e da infraestrutura física da instituição para aprender o conteúdo; a dependência de se relacionar apenas com turma mais homogênea (mesma idade, cultura, região...); a passividade em relação à recepção das informações; e o descompromisso e preocupação com o planejamento e organização do tempo de estudo. 


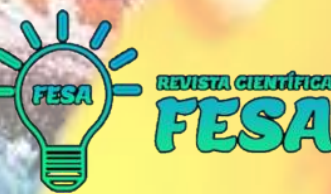

\section{PLATAFORMAS DE APRENDIZAGEM}

As plataformas de aprendizagem precisam ter um lugar especial neste debate, pois elas são soluções que tornaram a educação mais dinâmica, acessível e flexível que permitem que um número maior de alunos desfrute dos mesmos recursos, informações e saberes ali dispostos, fazendo os custos deste processo serem reduzidos, o que faz com que muitas empresas e instituições de ensino recorram a esse modelo de ensino e aprendizado.

As plataformas de ensino e aprendizagem são ferramentas/mídias que utilizam de recursos tecnológicos com finalidades educacionais, hospedando-se na web, permitindo a adesão de mais pessoas em diferentes locais, horários e dias. Por isso, adotar uma plataforma de aprendizagem é um meio de propiciar o ensino de forma mais dinâmica, já que combina diferentes formatos em um mesmo ambiente.

Com a ampliação dos recursos tecnológicos, cada vez mais recursos midiáticos são inseridos neste meio de ensino incluído: animações; chat; gamificação; vídeo; fórum; avaliações e tantas; testes e outras possibilidades que enriquecem a formação do aluno.

\section{CONSIDERAÇÕES FINAIS}

Neste escrito, discutiu-se sobre o papel do professor e do aluno, no que tange aos seus atos no processo de ensino e aprendizagem. Neste modelo de ensino-aprendizagem (EAD), dessa forma, notamos que ambos precisam ser parceiros, ativos, organizados e dispostos a superar obstáculos, visando atingir novos saberes e conhecimentos.

Foi tratado aqui sobre as diferenças entre a modalidade de ensino presencial e EAD, enfatizando, especialmente, a questão da flexibilidade, comodidade e custos que este modelo de "formação e capacitação" pode propiciar aos envolvidos.

Também foi apresentado um curto relato histórico deste processo e meio de ensino, bem como seus recursos fundamentais de suporte e organização dos conteúdos didáticos e das plataformas. 


\section{REFERÊNCIAS BIBLIOGRÁFICAS}

AZEVEDO, Wilson. Educação à distância na universidade do século XXI. 2000. Disponível em:www.aquifolium.com.br/educacional/artigos. Acesso em 06 de Maio de 2021.

MORAIS, Bruna Tavares de et al. A importância dos ambientes virtuais de aprendizagem - AVA e suas funcionalidades nas plataformas de ensino a distância EAD. Anais V CONEDU Campina Grande: Realize Editora, 2018. Disponível em: https://www.editorarealize.com.br/index.php/artigo/visualizar/45938. Acesso em: 27 jun. 2021.

KENSKI, Vani Moreira. Tecnologias e Ensino Presencial e a Distância: Práticas Pedagógicas. São Paulo: Papirus, 2003.

MORAES, Maria Cândida (Org). Educação a distância: fundamentos e práticas. Campinas, SP: Unicamp / Nied, 2002.

\section{APENDICE - MAPA MENTAL SOBRE AS DIFERENÇAS E SEMELHANÇAS ENTRE O ENSINO PRESENCIAL X EAD}

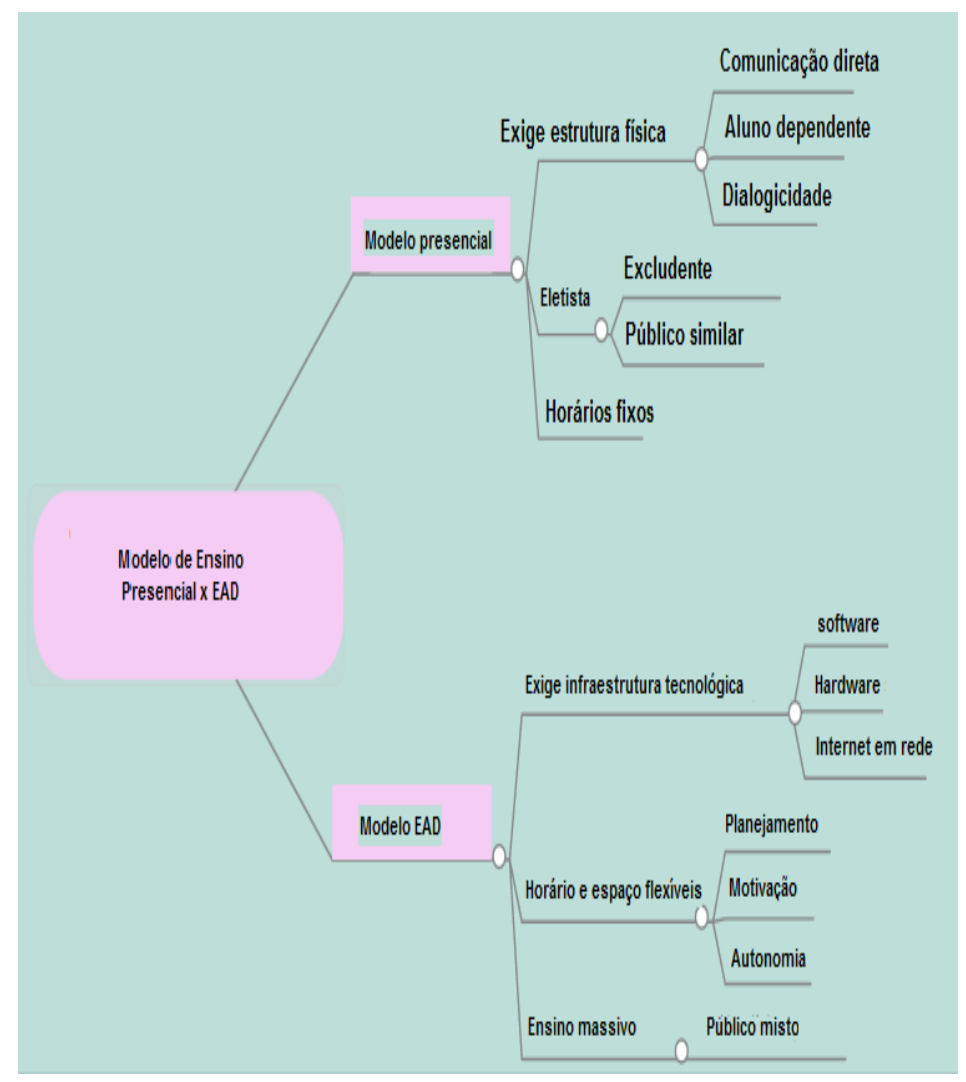

Fonte: Produção do Autor. 